\title{
Vatalanib Succinate
}

National Cancer Institute

\section{Source}

National Cancer Institute. Vatalanib Succinate. NCI Thesaurus. Code C74945.

The succinate salt of vatalanib, an anilinophthalazine derivative, with antineoplastic activity. Vatalanib binds to and inhibits the protein kinase domain of vascular endothelial growth factor receptors 1 and 2; both receptor tyrosine kinases are involved in angiogenesis. This agent also binds to and inhibits related receptor tyrosine kinases, including platelet-derived growth factor (PDGF) receptor, c-Kit, and c-Fms. 